\title{
A case of Multiple Endocrine Neoplasia Type 2A with a C634A Mutation and a L769L Polymorphism in RET Proto-oncogene
}

Min Jeong Kwon, Tae Kyoon Kim, Soon hee Lee, Jeong Hyun Park

Department of Internal Medicine, Busan paik Hospital, College of Medicine, Inje University

\section{INTRODUCTION}

Multiple endocrine neoplasia type $2(\mathrm{MEN}-2)$ is a complex hereditary disorder which confers a predisposition to the development of endocrine tumors. MEN-2 occurs owing to a germline mutation in the rearranged during transfection (RET) proto-oncogene that is transmitted in an autosomal dominant pattern. MEN2A, MEN2B and familial medullary thyroid cancer (FMTC) comprise the MEN-2 syndrome. The MEN2A complex comprises FMTC, pheochromocytma and primary hyperparathyroidism. MTC is usually the initial presenting feature of this complex and the prognosis of MEN2A is dependent on the stage of FMTC at diagnosis. Reported cases of MEN-2 have been identified in 500-1000 families and the prevalence is estimated to be 1 in 30,000. Specific RET mutations correlate with the onset of age and the aggressiveness of the disease. It has been reported that polymorphisms of RET may have a modifier effect on the presentation. We experienced a case of 27-year-old woman who was diagnosed with MEN2A having a C634A Mutation and a L769L Polymorphism in RET Proto-oncogene.

\section{CASE}

A 27-year-old woman presented with palpitation and orthostatic hypotension, with suspicion of a pheochromocytoma. Abdominal CT scan confirmed the presence large bilateral adrenal masses(maximum diameter of $2.9 \mathrm{~cm}$ for right mass and $7.1 \mathrm{~cm}$ for left mass) (Fig. 1).

Pheochromocytomas were diagnosed by ${ }^{131} \mathrm{I}-$ metaiodobenzylguanidine (MIBG) scan (Fig. 2), along with elevated urinary catecholamine and metabolite concentrations (Table 1). Her father died in a car accident in youth. Her mother remembered patient's aunt (father's sister) in Canada, had never seen, had total thyroidectomy in youth, MEN2A was strongly suspected.
Her basal serum calcitonin level was elevated (11.1 pg/ml). Serum PTH level, calcium and phosphorus were within normal range $(563.82 \mathrm{pg} / \mathrm{ml}, 9.3 \mathrm{mg} / \mathrm{dl}$, and 3.8 $\mathrm{mg} / \mathrm{dl}$ ). In neck ultrasound scan (Fig. 3A and 3B), a markedly hypoechoic thyroid nodule in right mid-lobe $(0.5 \mathrm{~cm})$ and a suspicious lesion for parathyroid adenoma in right inferior peri-thyroidal area $(0.7 \times 0.9 \times 1.6 \mathrm{~cm})$. Screening for the RET gene was performed after appropriate informed consent was obtained (approved by the Ethical Review Board for Human Genome Studies at Busanpaik Hospital), and, the C634A mutation $(1900 \mathrm{~T}>\mathrm{C})$ at exon 11 and a polymorphism in codon 769 (L769L, $2307 \mathrm{~T}>\mathrm{G}$ ) at exon 13 of the RET protooncogene(Table 2) were identified. Bilateral adrenal tumors were surgically resected, and the diagnosis of pheochromocytomas was confirmed by histological examination. She underwent total thyroidectomy and resection of parathyroid glands. Each one small medullary thyroid carcinoma in both thyroid lobes and a parathyroid adenoma of right inferior parathyroid gland were diagnosed by histological examination.

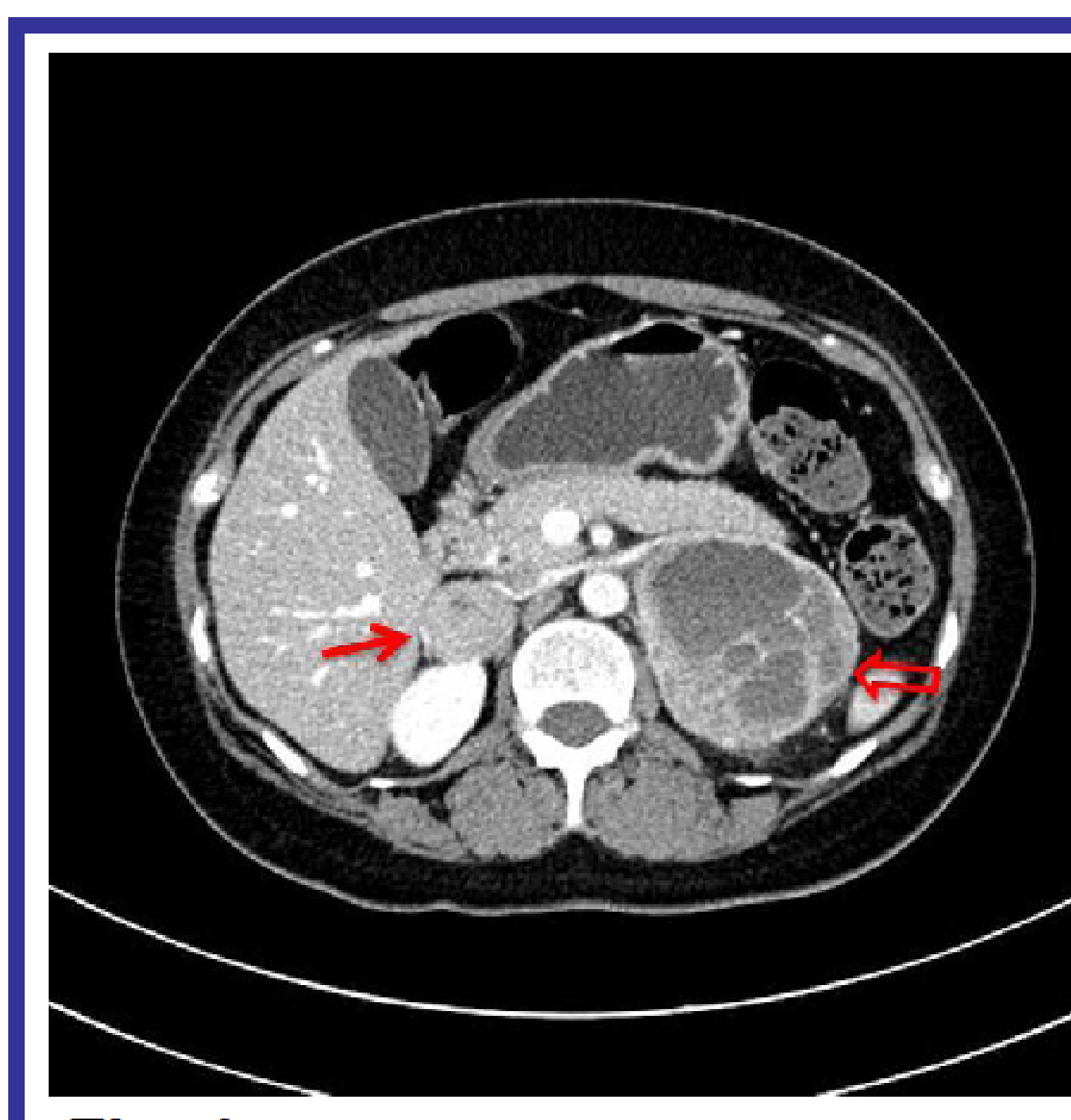
Fig. 1.

Computed tomography of abdomen shows right (arrow) and left (open arrow) adrenal tumors
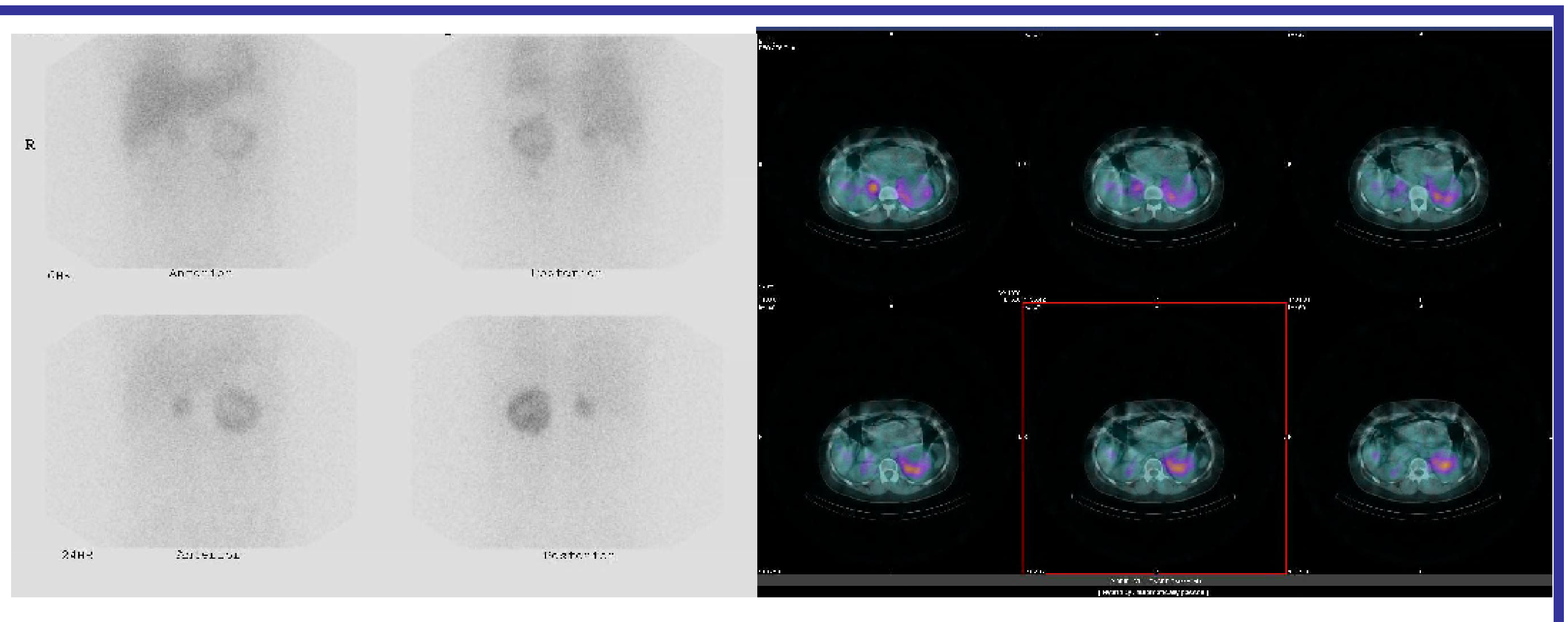

Fig. 2.

131 I-MIBG scan reveals abnormal uptakes indicating bilateral pheochromocytomas.
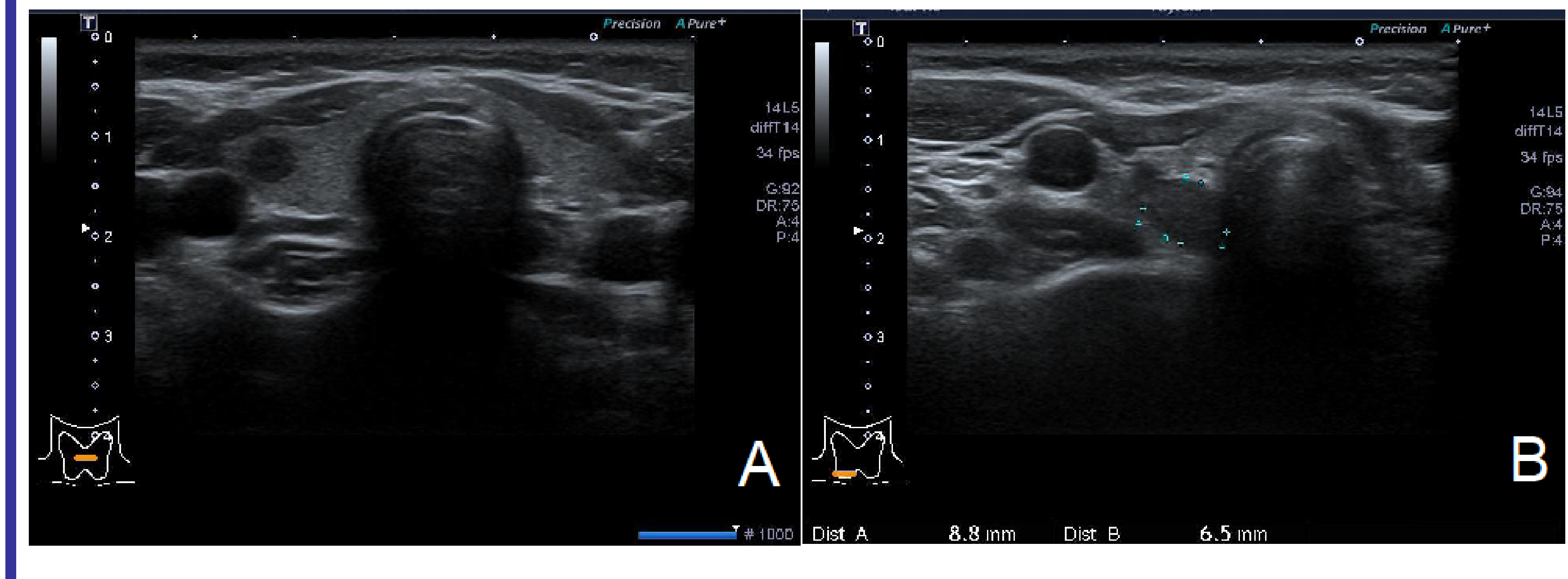

Fig. 3. Neck Ultrasound.

A, suspicious for a small malignant thyroid nodule with intraglandular location in right mid-lobe $(0.5 \mathrm{~cm})$ $\mathrm{B}$, suspicious for parathyroid adenoma in right inferior peri-thyroidal area $(0.7 \times 0.9 \times 1.6 \mathrm{~cm})$
Table 1.

Urinary catecholamine and metabolite level

\begin{tabular}{lll}
\hline & & $\begin{array}{l}\text { Reference } \\
\text { range }\end{array}$ \\
\hline Epinephrine & 234.8 & $0-20 \mu \mathrm{g} /$ day \\
\hline Norepinephrine & 497.9 & $15-80 \mu \mathrm{g} /$ day \\
\hline Dopamine & 494.0 & $65-400 \mu \mathrm{g} /$ day \\
\hline Metanephrine & 7572.0 & $52-341 \mu \mathrm{g} /$ day \\
\hline Normetanephrine & 7725.2 & $88-444 \mu \mathrm{g} /$ day
\end{tabular}

Table 2.

Genetic testing of the RET proto-oncogene

\begin{tabular}{c|cccccc}
\hline Gene & Exon & $\begin{array}{c}\text { Nucleotid } \\
\text { e change }\end{array}$ & $\begin{array}{c}\text { Amino } \\
\text { acid } \\
\text { change }\end{array}$ & Zygosity & Mutation effect \\
\hline RET & 11 & $1900 T>C$ & Cys634Arg & Hetero & Mutation \\
& 13 & $2307 T>$ G & Leu769Leu & Homo & Polymorphism \\
\hline
\end{tabular}

Normetanephrine $7725.2 \quad 88-444 \mu \mathrm{g} /$ day

\section{CONCLUSIONS}

Patients of MEN2A with a C634A mutation and a $\mathrm{L} 769 \mathrm{~L}$ polymorphism in RET proto-oncogene may be presented in younger age and have poor prognosis.

\section{References}

1. Gertner ME, Kebebew E. Multiple endocrine neoplasia type 2. Curr Treat Options Oncol 2004;2013:315-25

2. Conte-Devolx B, Niccoli P. Groupe d'étude des Tumeurs Endocrines. Clinical characteristics of multiple endocrine neoplasia. Bull Acad Natl Med 2010;2013:69-79

3. Marini F, Falchetti A, Del Monte F, et al. Multiple endocrine neoplasia type 2. Orphanet J Rare Dis 2006;2013:45

4. Bolino A, Schuffenecker I, Luo Y, et al. RET mutations in exons 13 and 14 of FMTC patients. Oncogene 1995;2013:2415-19 